Thabiea : Journal of Natural ScienceTeaching
Program Studi Tadris Ilmu Pengetahuan Alam
Institut Agama Islam Negeri Kudus
http://journal.stainkudus.ac.id/index.php/Thabiea
$p$-issn: 25808474

\title{
Pengembangan Soal Penalaran Model TIMSS untuk Mengukur High Order Thinking (HOT)
}

\author{
Indri Nurwahidah ${ }^{1, a}$ \\ ${ }^{1}$ Program Studi Pendidikan IPA, IKIP Veteran Semarang \\ aindrinur555@gmail.com
}

\begin{tabular}{ll}
\hline Kata Kunci & ABSTRAK \\
\hline Soal & Penelitian dilakukan untuk mengetahui ciri khas dan bentuk soal; \\
Reasoning & mengetahui pula validitas, reliabilitas, respon siswa serta hasil pengukuran \\
TIMSS & HOT terhadap soal penalaran model TIMSS untuk mengukur HOT siswa \\
HOT & yang dikembangkan. Metode yang digunakan adalah penelitian \\
& pengembangan. Produk berupa soal pilihan ganda serta alasan dari \\
& jawaban siswa. Respon siswa diperoleh dari angket respon siswa setelah \\
& menggunakan soal tersebut. Berdasarkan uji kelayakan produk dalam \\
& kriteria sangat baik. Ciri khas soal penalaran model TIMSS yaitu \\
& mengandung komponen-komponen penalaran mengacu pada TIMSS. \\
& Hasil uji validitas keseluruhan soal menunjukkan bahwa soal valid dan \\
& layak digunakan untuk mengukur HOT siswa. Hasil uji reliabilitas \\
& menunjukkan bahwa soal reliabel dan dapat digunakan dengan baik. \\
& Respon siswa setelah menggunakan soal dalam kategori sangat baik, \\
& diperoleh persentase sebesar 82,66\%. Hasil pengukuran HOT siswa masih \\
& dalam kategori rendah, pada SMP Negeri 8 Semarang sebesar 51,54\%, \\
& SMP Kartika III-2 Semarang sebesar 31,16\%, dan MTs NU Ungaran \\
& sebesar 47,68\%. Soal penalaran model TIMSS yang telah dikembangkan \\
& layak digunakan untuk mengukur HOT siswa.
\end{tabular}

\section{Keywords:}

Questions

Reasoning

TIMSS

HOT

\begin{abstract}
The research was conducted to determine the characteristics and forms of matter; similarly determine the validity, reliability, as well as the students' response to the measurement results HOT reasoning about TIMSS models to measure student HOT developed. The method used is the research development. Products in the form of multiple choice questions as well as the reasons of the students' answers. Student responses obtained from the questionnaire responses the students after using such a matter. Based on the criteria of due diligence in a very good product. Characteristic of reasoning about TIMSS models which contain components reasoning refers to the TIMSS. About the validity of the overall test results show that the question is valid and feasible to use to measure student HOT. Reliability test results indicate that the matter is reliable and can be used well. Student response after use problems in the excellent category, obtained a percentage of $82.66 \%$. HOT measurement results in the category of students is still low, at SMPN 8 Semarang amounted to $51.54 \%$, SMP Kartika III-2 Semarang amounted to $31.16 \%$, and the MTs NU amounted to $47.68 \%$ Ungaran. Problem reasoning models that have been developed decent TIMSS used to measure student HOT.
\end{abstract}

Copyright () 2018Institut Agama Islam Negeri Kudus. All Right Reserved

\section{Pendahuluan}

Kemampuan berpikir siswa harus dilatih sejak dini agar siswa mampu mengembangkan cara berpikirnya sehingga mampu memecahkan suatu masalah. Siswa yang kemapuan berpikirnya semakin berkembang akan mempunyai kemampuan berpikir tingkat tinggi atau High Order Thinking (HOT). Kemampuan berpikir siswa meliputi C1 hingga C6 pada taksonomi Bloom. Pada HOT pengaturan 
tingkatan berpikir yang paling banyak diterima dalam pendidikan adalah dengan menggunakan Taksonomi Bloom (Whittington,1995; Marzano,1997; Thompson,2008; Ramos,2013). Pada domain kognitif Taksonomi Bloom membagi tingkatan dari $\mathrm{C} 1$ hingga $\mathrm{C} 6$, dan HOT berada pada tingkatan yang cukup tinggi yaitu C4 sampai C6. Pengelompokan C1 hingga C6 dapat digunakan untuk membedakan tingkat berpikir siswa. Anderson \& Krathwohl (2001) menyatakan bahwa terjadi beberapa perbedaan pada taksonomi Bloom lama dan taksonomi Bloom revisi. Level berpikir HOT domain kognitif berada pada level analisis, sintesis, dan evaluasi pada taksonomi Bloom lama dan sampai level mencipta untuk taksonomi Bloom yang direvisi. Mullis \& Martin (2014) menyatakan bahwa tiga domain kognitif yang menggambarkan kemampuan berpikir siswa yang cenderung digunakan sebagai keterlibatan mereka dengan konten sains yaitu pengetahuan, penerapan dan penalaran. Menurut Mullis \& Martin (2014) item dalam domain penalaran mengharuskan siswa terlibat dalam penalaran ilmiah untuk menganalisis data, menarik kesimpulan, memecahkan masalah, dan memperluas pemahaman mereka pada situasi baru.

Berdasarkan wawancara dengan beberapa guru fisika SMP/MTs di Semarang, yaitu bapak Dwi Fajar Santoso, S.Pd, bu Isna Avif Nurain, S.Pd, dan bapak Arghob Khofya Haqiqi, S.Pd, menurut mereka kemampuan pemecahan masalah sebagian besar siswa masih dalam kategori rendah. Tidak banyak siswa yang mampu melakukan penalaran dan memecahkan masalah fisika yang kompleks. Tidak hanya itu, secara akademik nilai siswa pada mata pelajaran fisika masih tergolong rendah bila dibandingkan dengan mata pelajaran yang lain. Rendahnya nilai siswa salah satunya dikarenakan siswa belum terbiasa menyelesaikan soal yang membutuhkan penalaran. Hal tersebut perlu menjadi perhatian bagi para guru agar lebih sering melatih siswa dengan soal-soal yang membutuhkan penalaran. Rendahnya nilai siswa tersebut sesuai dengan hasil penelitian TIMSS (Trends in Mathematics and Science Study) yang menempatkan Indonesia di peringkat bawah.

TIMSS merupakan studi internasional yang dilakukan oleh IEA (International Association for the Evaluation of Educational Achievement). Penelitian tingkat internasional tersebut dilakukan setiap empat tahun sekali. Berdasarkan data TIMSS, siswa Indonesia untuk sains pada tahun 1999 menempati peringkat ke 32 dari 38 anggota, pada tahun 2003 berada di peringkat ke 37 dari 46 anggota, pada tahun 2007 berada di peringkat ke 35 dari 49 anggota, dan pada tahun 2011 menempati peringkat 40 dari 42 anggota.

Hasil TIMSS dapat dijadikan motivasi agar pendidikan di Indonesia semakin meningkat. Maka dari itu perlu ada perbaikan dalam berbagai hal pada sistem pendidikan di Indonesia, diantaranya program pendidikan, kurikulum, metode dan model pembelajaran, bahan ajar, penilaian Indonesia dan lain lain harus mampu mengejar ketinggalan dalam bidang pedidikan tersebut. Siswa harus dilatih agar mampu berpikir kritis sehingga memiliki kemampuan HOT atau berpikir tingkat tinggi. Heong, et. al., (2011) menyatakan bahwa keterampilan HOT merupakan aspek penting dalam proses pembelajaran, keterampilan berpikir dapat mempengaruhi kemampuan belajar, kecepatan dan efektivitas pembelajaran. Sebelum melakukan berbagai perbaikan dan peningkatan kemampuan berpikir siswa, perlu diketahui terlebih dahulu bagaimana kemampuan HOT siswa. Setelah diketahui pada level mana siswa berada maka dapat diambil tindakan oleh guru utuk meningkatkan kemampuan HOT tersebut.

Penelitian yang dilakukan Kurniawati (2014), menunjukkan bahwa kemampuan HOT mahasiswa pada ranah kognitif $\mathrm{C} 4$ sampai $\mathrm{C} 6$ kurang dari $50 \%$ pada pertemuan pertama. Guru harus melihat proses belajar siswa dan lebih mengeksplore kemampuan berpikir siswa agar kemampuan siswa dapat lebih berkembang. Proses pengembangan HOT melalui berpikir kritis menurut Duron, Limbach \& Waugh (2006) ada lima tahap, yaitu tentukan tujuan pembelajaran; ajarkan melalui 
pertanyaan; praktek sebelum anda menilai; review, memperbaiki, dan meningkatkan; dan memberikan umpan balik dan penilaian pembelajaran. Thompson (2008) menyatakan bahwa guru masih mengalami kesulitan dalam menciptakan item tes keterampilan berpikir tingkat tinggi (HOT). Maka dari itu peneliti bermaksud akan mengadakan penelitian tentang pengembangan soal penalaran model TIMSS untuk mengukur HOT siswa.
Penelitian ini merupakan Research and Development. Langkah-langkah yang digunakan dalam penelitian diadaptasi dari langkah-langkah Borg \& Gall (2003) meliputi, penelitian pendahuluan, perencanaan, pengembangan draf produk, uji coba skala kecil, dan uji coba skala luas. Uji coba skala luas dilaksanakan di beberapa SMP/MTs wilayah Semarang. Desain penilaian produk ditunjukkan seperti pada Gambar 1.

\section{Metode}

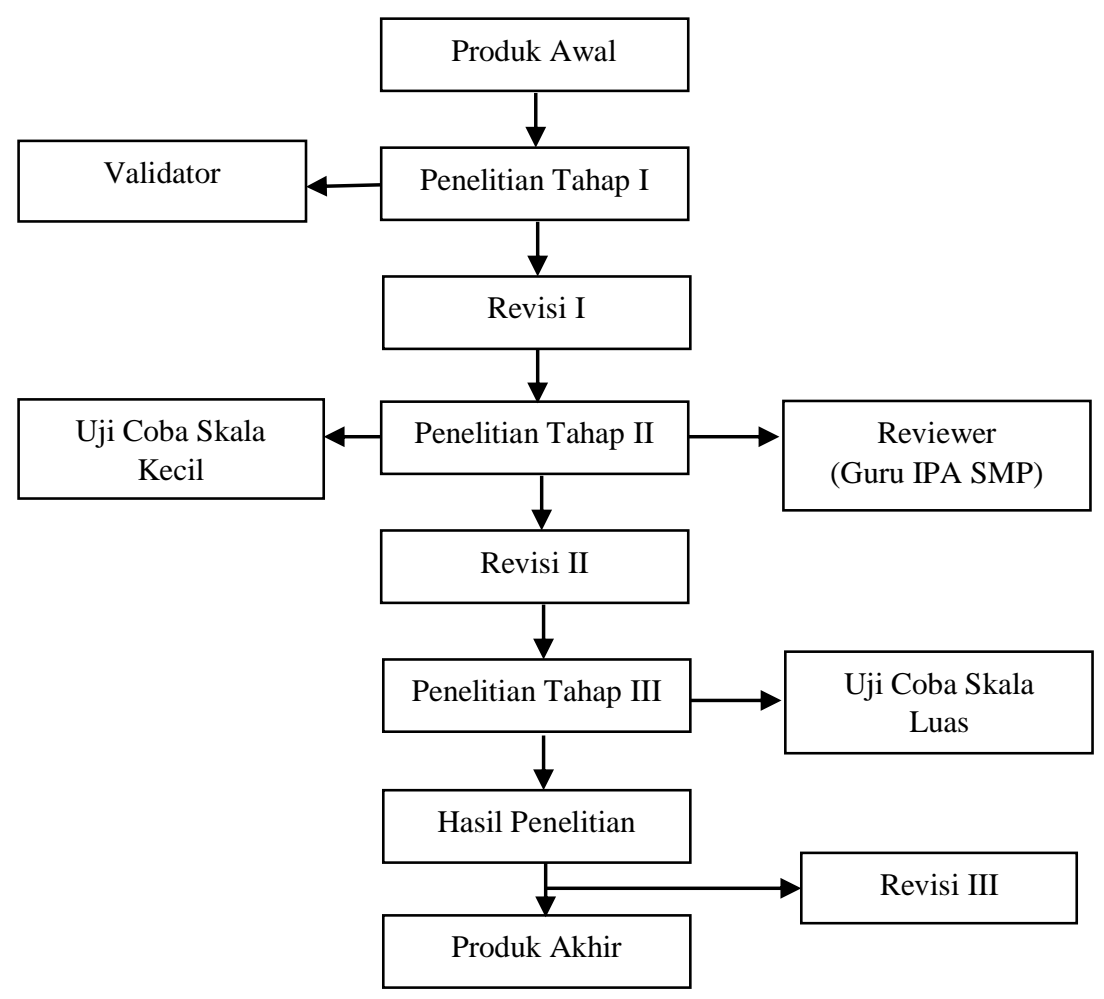

Gambar 1. Desain Penilaian Produk

Instrumen yang digunakan pada penelitian ini yaitu uji validitas, reliabilitas, daya beda, tingkat kesukaran dan angket. Pengembangan soal yang dilakukan yakni dengan cara menganalisis sosl-soal TIMSS yang telah ada, mempelajari polanya kemudian membuat soal serupa disesuaikan dengan materi dan kurikulum yag berlaku saat ini. Soal yang dibuat juga disesuaikan dengan kompenen penalaran TIMSS menurut Mullis \& Martin, (2014). Soal yang dikembangkan juga disesuaikan dengan komponen HOT menurut
Marzano (1997) agar dapat digunakan untuk mengukur kemampuan HOT siswa.

\section{Hasil dan pembahasan}

Produk yang dihasilkan dari penelitian berupa soal penalaran model TIMSS yang telah dikembangkan berisi 40 soal pilihan ganda disertai dengan uraian alasan dari setiap jawaban tersebut. Contoh isi dari soal HOT yang telah dikembangkan dapat dilihat pada Gambar 2. 


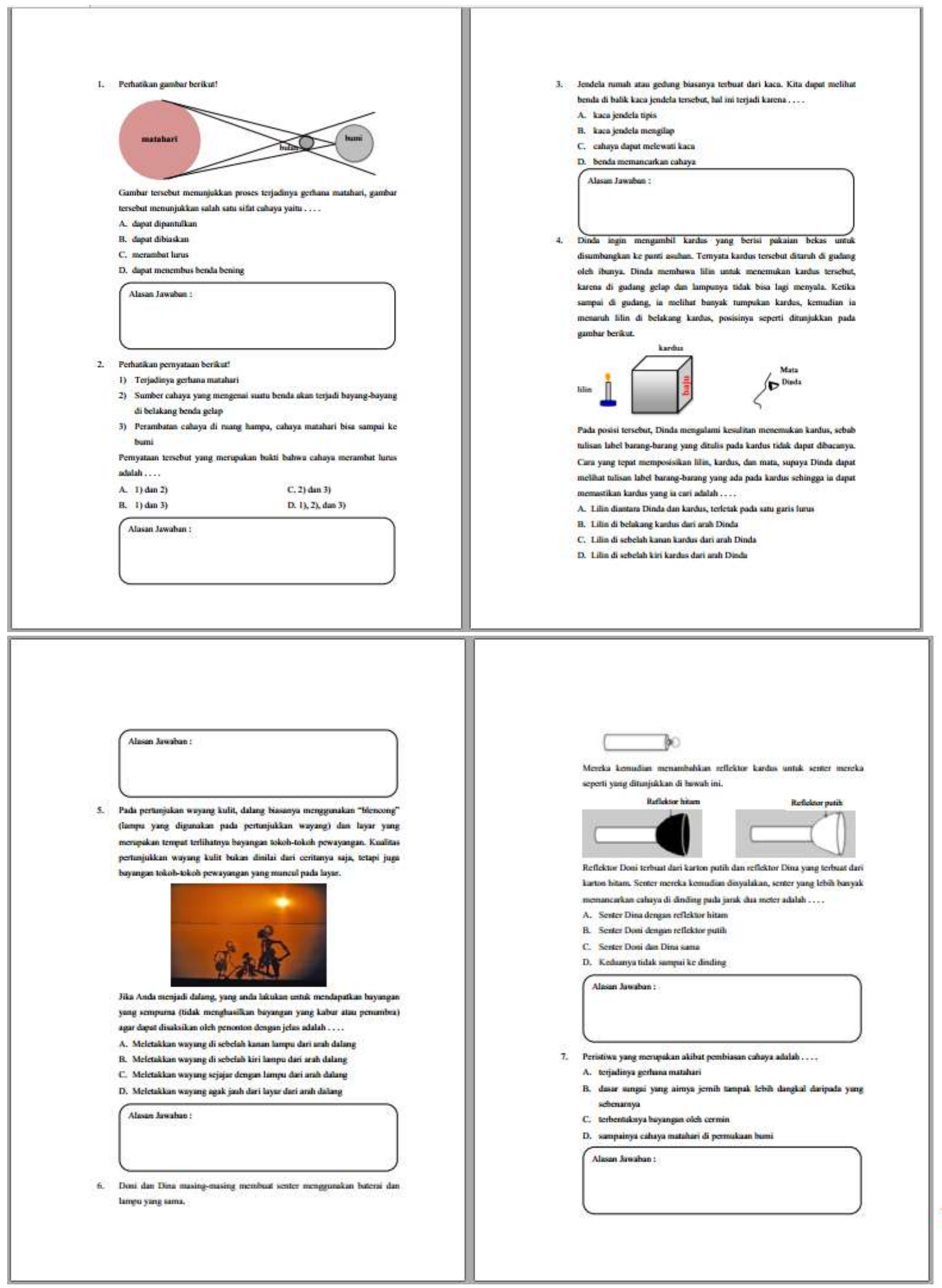

Gambar 2. Contoh Soal HOT yang telah Dikembangkan

Produk dikembangkan berdasarkan soal-soal TIMSS yang telah ada dan disesuaikan dengan kebutuhan dan keadaan di sekolah. Soal TIMSS yang telah ada dianalisis bentuk, pola dan ciri-cirinya. Selanjutnya soal dikembangkan, dibuat dengan bahasa Indonesia 
agar lebih mudah dipahami siswa, dibuat dalam bentuk yang sama dan dengan materi yang telah ditentukan.

Ciri khas dari soal penalaran model TIMSS yang dikembangkan yaitu berupa tes pilihan ganda yang mengharuskan siswa menuliskan alasan pilihan jawabannya. Hal tersebut membuat siswa lebih serius dan tertantang dalam menyelesaikan soal, karena penilaian tidak hanya pada pilihan jawabannya saja tetapi juga pada alasan dari jawaban tersebut. Selain itu, dalam penyusunan soal penalaran model TIMSS yang dikembangkan ini juga menggunakan komponen-komponen penalaran yang ada pada TIMSS yaitu analisis, sintesis, desain investigasi, merumuskan pertanyaan/hipotesis/prediksi, evaluasi, membuat kesimpulan, generalisasi, dan justify.

Komponen penalaran TIMSS dapat dikaitkan dengan kompetensi HOT menurut Marzano (1997), sehingga produk yang dihasilkan dapat digunakan untuk mengukur kompetensi HOT. Soal penalaran model TIMSS yang telah dikembangkan mengandung indikator HOT, yaitu membandingkan, mengklasifikasikan, penalaran induktif, penalaran deduktif, kesalahan analisis, membangun gagasan pendukung, menganalisis secara perspektif, mengabstraksi, mengambil keputusan, investigasi/menyelidiki, memecahkan masalah, menyelidiki percobaan, mengembangkan gagasan. misalnya soal nomor 1 mewakili kompetensi HOT yaitu analisis dan evaluasi, soal nomor 2 mengandung kompetensi analisis dan membuat kesimpulan, dan soal nomor 3 mengandung kompetensi analisis dan evaluasi.

Produk yang berisi soal berjumlah 40 nomor tersebut sudah dapat mewakili semua kompetensi penalaran yang ada pada TIMSS sehingga dapat digunakan untuk mengukur semua kompetensi pada HOT. Indikator HOT pada soal penalaran model TIMSS dapat dilihat pada Tabel 1.
Tabel 1. Indikator HOT pada Soal Penalaran Model TIMSS yang Dikembangkan

\begin{tabular}{|c|c|c|}
\hline Kompetensi & Definisi & No Soal \\
\hline Membandingkan & $\begin{array}{l}\text { Mengidentifikasi } \\
\text { dan } \\
\text { mengartikulasikan } \\
\text { persamaan dan } \\
\text { perbedaan suatu } \\
\text { hal }\end{array}$ & $\begin{array}{l}6,8,21,30, \\
34\end{array}$ \\
\hline Mengklasifikasikan & $\begin{array}{l}\text { Pengelompokan } \\
\text { sesuatu ke dalam } \\
\text { kategori } \\
\text { berdasarkan } \\
\text { anggapan mereka }\end{array}$ & $\begin{array}{l}2,7,8,9,16 \\
26,30,33,34\end{array}$ \\
\hline Penalaran induktif & $\begin{array}{l}\text { Menyimpulkan } \\
\text { generalisasi atau } \\
\text { prinsip-prinsip } \\
\text { dari informasi atau } \\
\text { observasi }\end{array}$ & $\begin{array}{l}1,7,9,14, \\
16,21,22, \\
23,24,25,28\end{array}$ \\
\hline Penalaran deduktif & $\begin{array}{l}\text { Menggunakan } \\
\text { generalisasi dan } \\
\text { prinsip-prinsip } \\
\text { untuk } \\
\text { menyimpulkan } \\
\text { kesimpulan tak } \\
\text { tertulis mengenai } \\
\text { informasi atau } \\
\text { situasi tertentu }\end{array}$ & $\begin{array}{l}3,8,18,19, \\
20,26,33, \\
35,36,37, \\
38,39,40\end{array}$ \\
\hline Kesalahan analisis & $\begin{array}{l}\text { Mengidentifikasi } \\
\text { dan } \\
\text { mengartikulasikan } \\
\text { kesalahan dalam } \\
\text { pemikiran }\end{array}$ & $\begin{array}{l}8,15,26,30 \\
34\end{array}$ \\
\hline $\begin{array}{l}\text { Membangun } \\
\text { gagasan } \\
\text { pendukung }\end{array}$ & $\begin{array}{l}\text { Membangun } \\
\text { sistem dukungan } \\
\text { pada pernyataan }\end{array}$ & $\begin{array}{l}2,9,11,13, \\
17,22,23, \\
24,25,26,28\end{array}$ \\
\hline $\begin{array}{l}\text { Menganalisis } \\
\text { secara perspektif }\end{array}$ & $\begin{array}{l}\text { Mengidentifikasi } \\
\text { berbagai } \\
\text { perspektif tentang } \\
\text { masalah dan } \\
\text { memeriksa alasan } \\
\text { atau logika di } \\
\text { balik masing- } \\
\text { masing }\end{array}$ & $\begin{array}{l}3,11,19,22 \\
23,24,31,32\end{array}$ \\
\hline Mengabstraksi & $\begin{array}{l}\text { Mengidentifikasi } \\
\text { dan } \\
\text { mengartikulasikan } \\
\text { tema dasar atau } \\
\text { pola umum } \\
\text { informasi }\end{array}$ & $\begin{array}{l}7,21,23,24 \\
26,29\end{array}$ \\
\hline $\begin{array}{l}\text { Mengambil } \\
\text { keputusan }\end{array}$ & $\begin{array}{l}\text { Menghasilkan dan } \\
\text { menerapkan } \\
\text { kriteria untuk } \\
\text { memilih antara } \\
\text { alternatif yang } \\
\text { tampaknya sama }\end{array}$ & $6,9,15,22$ \\
\hline $\begin{array}{l}\text { Investigasi/ } \\
\text { menyelidiki }\end{array}$ & $\begin{array}{l}\text { Mengidentifikasi } \\
\text { dan } \\
\text { menyelesaikan } \\
\text { masalah tentang } \\
\text { kebingungan atau } \\
\text { kontradiksi }\end{array}$ & $\begin{array}{l}4,5,17,26 \\
27,29\end{array}$ \\
\hline $\begin{array}{l}\text { Memecahkan } \\
\text { masalah }\end{array}$ & $\begin{array}{l}\text { Mengatasi kendala } \\
\text { atau membatasi } \\
\text { kondisi yang } \\
\text { dalam perjalanan }\end{array}$ & $\begin{array}{l}4,5,14,17, \\
32\end{array}$ \\
\hline
\end{tabular}




\begin{tabular}{|c|c|c|}
\hline \multirow{3}{*}{$\begin{array}{l}\text { Menyelidiki } \\
\text { percobaan }\end{array}$} & \multicolumn{2}{|l|}{ mengejar tujuan } \\
\hline & $\begin{array}{l}\text { Menghasilkan dan } \\
\text { pengujian }\end{array}$ & $\begin{array}{l}6,10,11,12, \\
13,16,17,\end{array}$ \\
\hline & $\begin{array}{l}\text { penjelasan } \\
\text { fenomena yang } \\
\text { diamati }\end{array}$ & \\
\hline $\begin{array}{l}\text { Mengembangkan } \\
\text { gagasan }\end{array}$ & $\begin{array}{l}\text { Mengembangkan } \\
\text { produk yang unik }\end{array}$ & $\begin{array}{l}6,23,24,25 \\
27,29,31,34\end{array}$ \\
\hline & $\begin{array}{l}\text { atau proses yang } \\
\text { memenuhi }\end{array}$ & \\
\hline & $\begin{array}{l}\text { kebutuhan yang } \\
\text { dirasakan }\end{array}$ & \\
\hline
\end{tabular}

Produk divalidasi oleh tiga validator dan dua reviewer yang memiliki disiplin ilmu sesuai dengan materi yang diteliti. Tiga validator tersebut merupakan dosen IPA khususnya Fisika Fakultas Matematika dan Ilmu Pengetahuan Alam Universitas Negeri Semarang. Dua reviewer merupakan guru IPA di SMP/MTs di wilayah Semarang yaitu Guru IPA SMP Negeri 8 Semarang dan Guru IPA MTs NU Ungaran Kabupaten Semarang. Hasil validasi terlihat pada Tabel 2 .
Tabel 2. Hasil Validasi

\begin{tabular}{llccl}
\hline No. & Komponen & Skor & $\begin{array}{c}\text { Persentase } \\
(\mathbf{\%})\end{array}$ & Kriteria \\
\hline 1 & Isi Soal & 53,25 & 84,38 & $\begin{array}{l}\text { Sangat } \\
\text { Baik }\end{array}$ \\
2 & $\begin{array}{l}\text { Penyajian } \\
\text { Soal }\end{array}$ & 24,25 & 86,61 & $\begin{array}{l}\text { Sangat } \\
\text { Baik }\end{array}$ \\
3 & $\begin{array}{l}\text { Bahasa yang } \\
\text { digunakan } \\
\text { pada soal }\end{array}$ & 12,50 & 78,13 & \\
& & & $\begin{array}{l}\text { Baik } \\
\text { Sangat } \\
\text { Baik }\end{array}$ \\
\hline
\end{tabular}

Berdasarkan hasil validasi soal yang telihat pada Tabel 1 menunjukkan bahwa soal penalaran model TIMSS yang telah dikembangkan berada pada kriteria sangat baik dan layak digunakan untuk penelitian. Hal tersebut menunjukkan bahwa soal tersebut valid, artinya soal tersebut dapat mengukur kompetensi HOT siswa. Uji coba skala luas dilakukan pada siswa kelas VIII di tiga sekolah menengah pertama di wilayah Semarang.

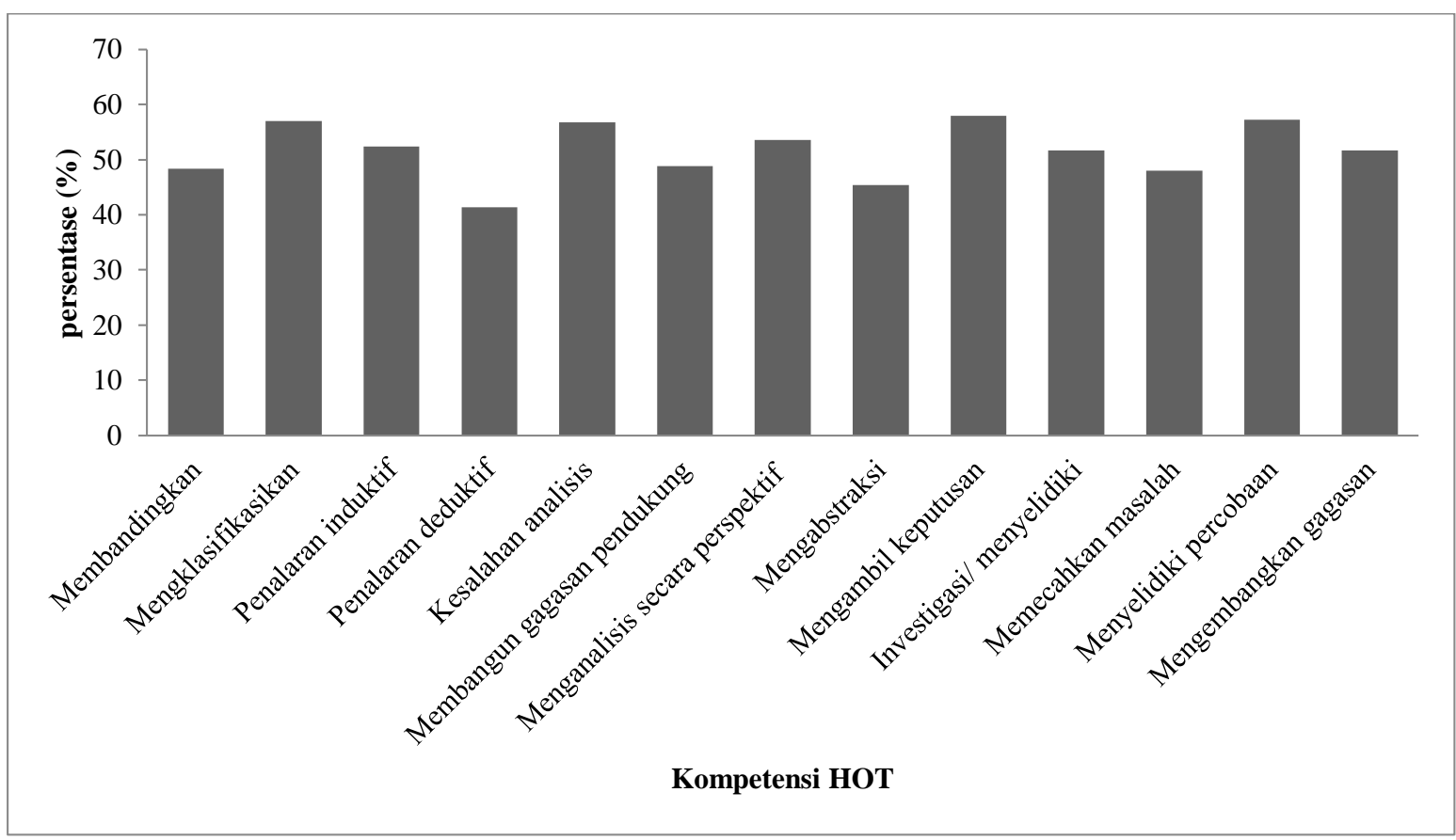

Gambar 2. Kompetensi HOT di SMP Negeri 8 Semarang

Berdasarakan Gambar 2 terlihat bahwa dari ketiga belas komponen memiliki rata-rata persentase yang rendah, sehingga kompetensi
HOT siswa SMP Negeri 8 Semarang berada pada kategori kurang. 


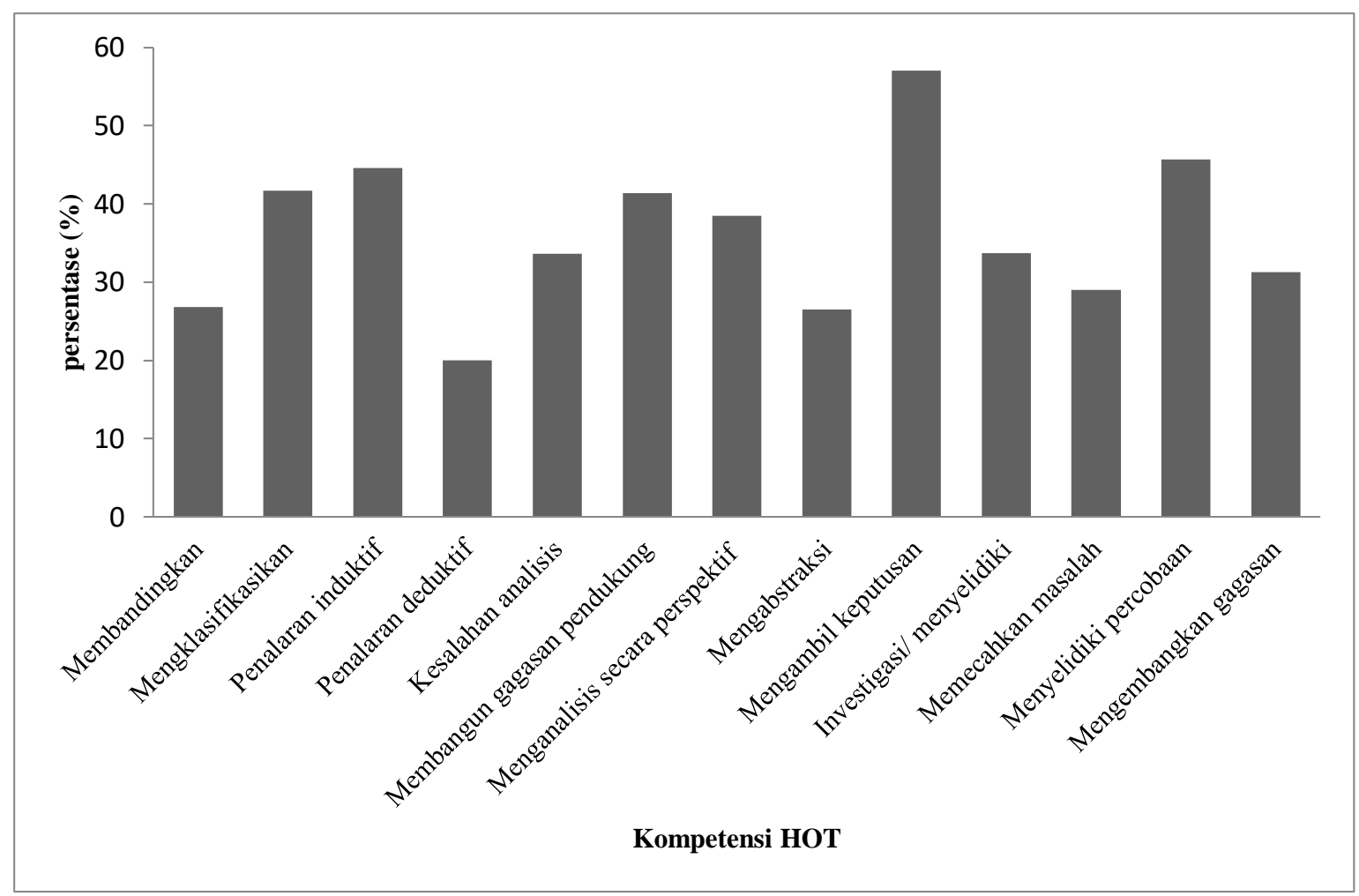

Gambar 3. Kompetensi HOT di SMP Kartika III-2 Semarang

Berdasarakan Gambar 3 terlihat bahwa dari ketiga belas komponen memiliki rata-rata persentase yang sangat rendah, sehingga kompetensi HOT siswa SMP Kartika III-2

Semarang berada pada kategori sangat kurang.

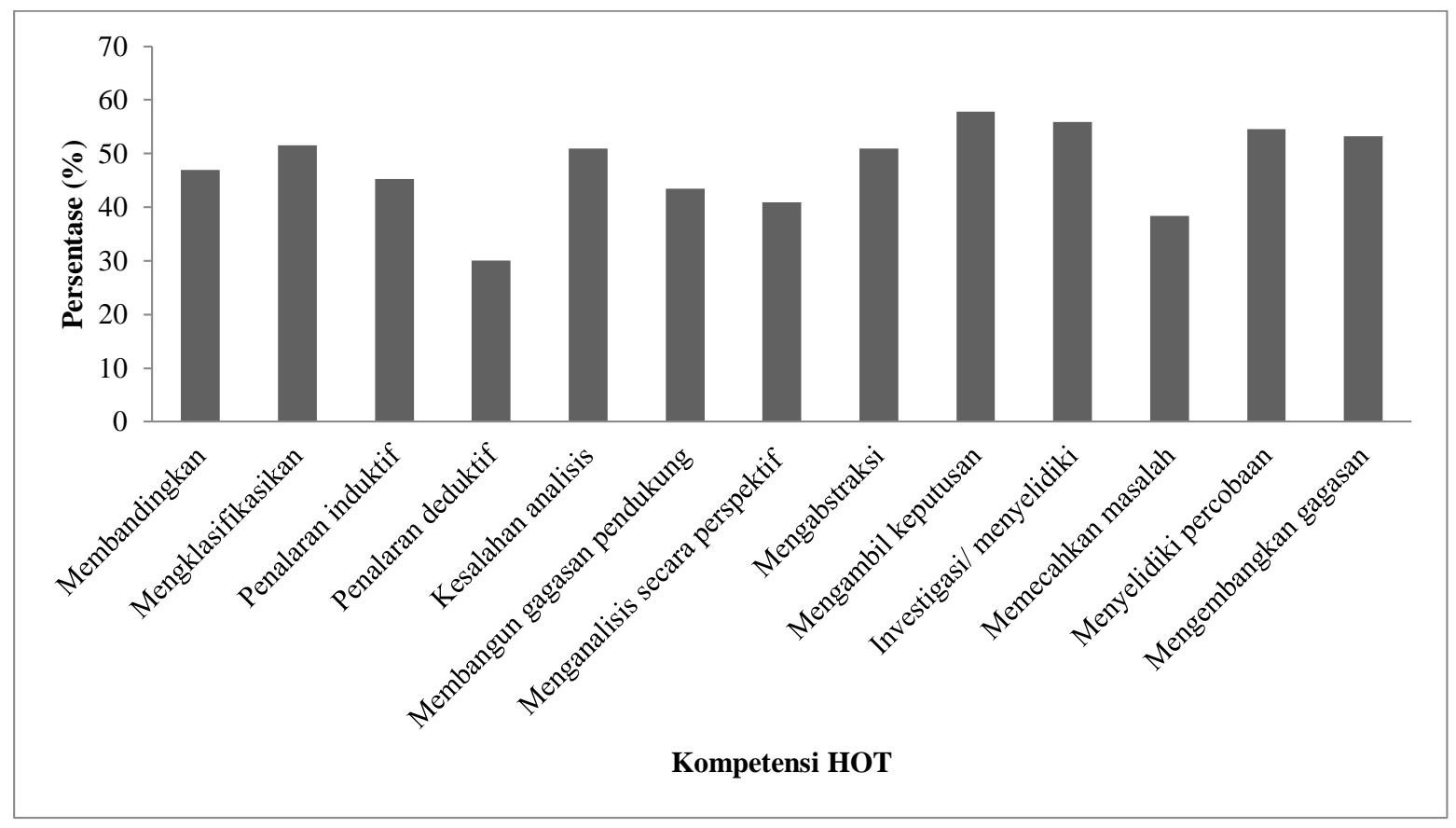

Gambar 4. Kompetensi HOT di MTs NU Ungaran

Berdasarkan Gambar 4, terlihat persentase rata-rata dari ketiga belas komponen di MTs NU Ungaran tidak jauh berbeda dengan
SMP Negeri 8 Semarang maupun SMP Kartika III-2 Semarang yaitu berada pada kategori kurang atau rendah. 


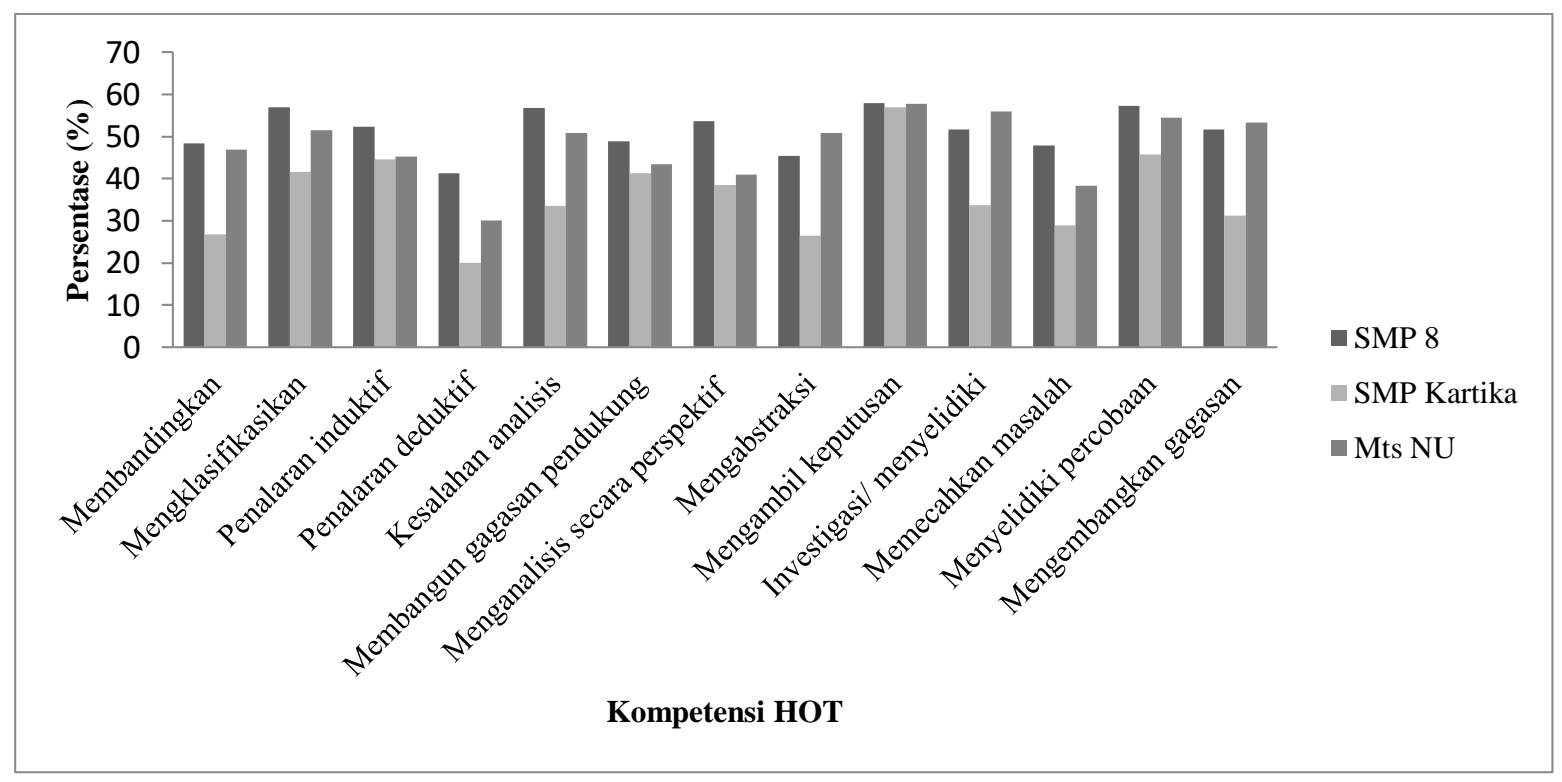

Gambar 5. Perbandingan Kompetensi HOT

Gambar 5 merupakan grafik perbandingan kompetensi HOT siswa pada ketiga sekolah, yaitu SMP Negeri 8 Semarang, SMP Kartika III-2 Semarang, dan MTs NU Ungaran. Grafik pada Gmbar 6 menunjukkan bahwa kompetensi HOT siswa pada ketiga sekolah hampir sama. Hasil rata-rata pengukuran HOT pada ketiga sekolah berada pada kategori kurang. Komponen yang paling dikuasai siswa yaitu komponen mengambil keputusan dan yang paling tidak dikuasai siswa yaitu pada komponen penalaran deduktif. Rendahnya kompetensi HOT siswa ini senada dengan penelitian yang dilakukan oleh Heong, Yunos, \& Noraini (2010) yang menunjukkan bahwa siswa memiliki persepsi tingkat penguasaan dan aplikasi HOT pada tingkat rendah.

Menurut Limbach \& Waugh kemampuan HOT siswa dapat ditingkatkan dengan cara menciptakan lingkungan belajar yang berpusat pada siswa. Polly \& Ausband (2009) menyatakan bahwa kompetensi HOT diperlukan untuk menggiring siswa agar dapat berkontribusi dalam kemajuan teknologi. Kemampuan HOT dapat dilatih melalui berbagai hal, salah satunya diawali dengan mendorong siswa agar mamapu berpikir kritis. Berawal dari berpikir kritis selanjutnya akan berkembang menuju berpikir tingkat tinggi atau
HOT. Duron, Limbach, \& Waugh (2006) menyatakan bahwa ada 5 langkah yang bisa dilakukan untuk melatih berpikir kritis, yang pertama, tentukan tujuan pembelajaran; ajarkan melalui pertanyaan; praktek sebelum anda menilai; review, memperbaiki, dan meningkatkan; dan memberikan umpan balik dan penilaian pembelajaran.

Respon siswa terhadap produk yang dikembangkan dilakukan dengan menggunakan angket respon siswa. Hasil respon siswa terhadap produk yang dikembangkan dapat dilihat pada Tabel 3.

Tabel 3. Respon Siswa terhadap Soal HOT

\begin{tabular}{|c|c|c|c|}
\hline No & Komponen & $\begin{array}{l}\text { Persentase } \\
\text { rata-rata } \\
(\%) \\
\end{array}$ & Keterangan \\
\hline 1 & $\begin{array}{l}\text { Tampilan huruf dapat } \\
\text { dibaca dengan jelas }\end{array}$ & 92,38 & Baik Sekali \\
\hline 2 & $\begin{array}{l}\text { Bahasa yang } \\
\text { digunakan } \\
\text { menggunakan kaidah } \\
\text { penulisan bahasa } \\
\text { Indonesia yang benar }\end{array}$ & 84,97 & Baik Sekali \\
\hline 2 & $\begin{array}{l}\text { Tidak terdapat } \\
\text { kalimat yang ambigu } \\
\text { (memiliki makna } \\
\text { ganda) dalam soal }\end{array}$ & 77,62 & Baik \\
\hline 4 & $\begin{array}{l}\text { Penyajian soal } \\
\text { menggunakan kata- } \\
\text { kata familiar (tidak } \\
\text { asing) dengan siswa }\end{array}$ & 76,51 & Baik \\
\hline 5 & $\begin{array}{l}\text { Gambar yang terdapat } \\
\text { pada soal jelas }\end{array}$ & 85,20 & Baik Sekali \\
\hline
\end{tabular}




\begin{tabular}{|c|c|c|c|}
\hline 6 & $\begin{array}{l}\text { Tampilan soal } \\
\text { menarik }\end{array}$ & 80,33 & Baik Sekali \\
\hline 7 & $\begin{array}{l}\text { Terdapat gambar, } \\
\text { tabel dan sejenisnya } \\
\text { yang membantu } \\
\text { memperjelas soal }\end{array}$ & 86,89 & Baik Sekali \\
\hline 8 & $\begin{array}{l}\text { Bahasa pada soal } \\
\text { mudah dipahami }\end{array}$ & 80,08 & Baik Sekali \\
\hline 9 & $\begin{array}{l}\text { Petunjuk dalam soal } \\
\text { dapat dipahami } \\
\text { dengan mudah }\end{array}$ & 79,84 & Baik \\
\hline 10 & $\begin{array}{l}\text { Tulisan yang terdapat } \\
\text { dalam soal jelas }\end{array}$ & 81,48 & Baik Sekali \\
\hline 11 & $\begin{array}{l}\text { Angka-angka yang } \\
\text { terdapat dalam soal } \\
\text { jelas }\end{array}$ & 81,74 & Baik Sekali \\
\hline 12 & $\begin{array}{l}\text { Soal membutuhkan } \\
\text { penalaran untuk } \\
\text { menyelesaikannya }\end{array}$ & 81,57 & Baik Sekali \\
\hline 13 & $\begin{array}{l}\text { Soal dapat menggali } \\
\text { pengetahuan siswa }\end{array}$ & 85,99 & Baik Sekali \\
\hline \multicolumn{2}{|c|}{ Rata-rata Persentase (\%) } & 82,66 & Baik Sekali \\
\hline
\end{tabular}

Berdasarkan Tabel 2, terlihat respon siswa terhadap soal penalaran model TIMSS yang telah dikembangkan. Para siswa pada tiga sekolah tersebut menyambut baik dengan adanya soal penalaran model TIMSS yang dikembangkan ini. Dengan demikian soal dianggap sudah layak untuk diujikan kepada mereka. Selain itu, soal penalaran model TIMSS yang telah dikembangkan dikatakan layak digunakan karena berdasarkan uji validitas soal dinyatakan valid, uji reliabilitas menunjukkan soal reliabel, uji daya beda soal baik, dan tingkat kesukaran soal juga merata.

\section{Simpulan}

Berdasarkan penelitian yang telah dilakukan dapat diambil simpulan bahwa ciri khas soal penalaran model TIMSS yang dikembangkan yaitu soal berupa tes tertulis pilihan ganda disertai uraian alasan dari pilihan jawabannya. Soal mengandung komponen-komponen penalaran yang ada pada TIMSS yaitu analsis, sintesis, desain investigasi, merumuskan pertanyaan/ hipotesis/prediksi, evaluasi, membuat kesimpulan, generalisasi, dan justify. Soal layak digunakan untuk mengukur HOT siswa karena berdasarkan validasi menunjukkan hasil yang sangat baik. Berdasarkan uji validitas menunjukkan bahwa soal penalaran model TIMSS yang dikembangkan valid dan uji reliabilitas menunjukkan bahwa soal reliabel dan dapat digunakan dengan baik. Respon siswa setelah menggunakan soal penalaran model TIMSS yang telah dikembangkan sangat baik. Kompetensi HOT siswa SMP/MTs beberapa sekolah di Semarang masih tergolong rendah.

\section{Ucapan Terima Kasih}

Pada kesempatan ini, penulis mengucapkan terima kasih kepada kepada Kepala SMP Negeri 8 Semarang, Kepala SMP Kartika III-2 Semarang, dan Kepala MTs NU Ungaran beserta guru IPA dan siswa yang telah membantu terlaksananya penelitian ini. Selain itu penulis juga mengucapkan terima kasih kepada semua pihak yang telah membantu yang tidak dapat kami sebutkan satu per satu.

\section{Referensi}

Anderson, O. W. \& Krathwohl, D. 2001. A Taxonomy for Learning, Teaching and Assessing. New York: Longman Inc.

Borg, W.R. \& Gall, M.D. Gall. 2003. Educational Research: An Introduction, Seventh Edition. New York: Longman.

Heong, Y. M., Yunos,J. B., \& Noraini, B.O. 2010. The Perception Of Student On Mastering The Level Of Higher Order Thinking Skills In Technical Education Subjects. RCEE \& RHEd :1-6

Heong, Y.M., Othman, W.D., Yunos, J.B., Kiong, T.T., Hassan, R., \& Mohamad, M.M. 2011. The Level of Marzano Higher Order Thinking Skills Among Technical Education Students. International Journal of Social and Humanity, 1(2):121-125

Kurniawati, W. 2014. Pengembangan Perangkat Perkuliahan IPA 2. Dengan Pendekatan Problem Based Learning Untuk Meningkatkan Keterampilan Higher Order Thinking Mahasiswa Program Studi Pendidikan Guru Sekolah Dasar. Journal of Elementary School, 1(1): 5566

Limbach, B. \& Waugh, W. Developing Higher Level Thinking. Journal of Instructional Pedagogies

Marzano, R. J.,. Pickering, D. J, Arredondo, D. E., Blackburn, G. J., Brandt, R. S, Moffett, C. A., Paynter, D. E., Pollock, J. E., \& Whisler, J. S. 1997. "Dimension of 
Learning Trainer's Manual," 2nd ed, Aurora, Colorado: McREL

Mullis, I. \& Martin, M. O. 2014. TIMSS Advanced 2015 Assesment framework. Chesnut Hills: Boston College.

Polly, D. \& Ausband, L. 2009. Developing Higher-Order Thinking Skills through WebQuests. Journal of Computing in Teacher Education. 26(1):29-34

Ramos, J. L. S., Dolipas, B. B. \& Villamor B. B. 2013. Higher Order Thinking Skills and Academic Performance in Physics of
College Students: A Regression Analysis. International Journal of Innovative Interdisciplinary Research. 4

Thompson, T. 2008. Mathematics Teachers Interpretation of Higher Order Thinking in Blooms Taxonomy. IEJME, 3(2).

Whittington M. S. 1995. Higher Order Thinking Opportunities Provided By Professors In College of Agriculture Classrooms. Journal of Agricultural Education: 36(4) 